accident-rate is reduced, and there is no doubt that it increases the confidence of road users. As to the question of yellow versus white headlamps, careful experiments have led to the conclusion that, for equal beam intensity, there is no significant difference in revealing power nor in estimates of glare, and it is not true that yellow light penetrates fog better than white.

The general discussion evoked by the papers which have been summarized was confined to the subjects of fluorescent and of street and vehicle lighting. The chairman, Dr. R. S. Creed, mentioned that difficulty in reading meniscus gauges under fluorescent lighting was within his knowledge, although this may have been due simply to misplecement of the lights. Dr. Floyd pointed out that lamps of different colour temperature give different colour-rendering and, occasionally, a critical contrast might be weakened by the light from one type of lamp although not by another. He had investigated a variety of complaints against fluorescent lighting, but they were often expressions of dissatisfaction with other conditions, or they were due to conditions of lighting not necessarily produced by using fluorescent lamps. In reply to speakers who asked whether ocular illeffects resulted from long-term exposure to fluorescent lighting, Mr. Weston said that there is no evidence of this. There had been a few cases of ocular affections occurring soon after a change from filament to fluorescent lighting, and those affected had wrongly blamed the lighting; he mentioned one such case which was demonstrably due to a bacterial infection. When, as now, many changes to fluorescent lighting are taking place, it would be surprising if there were no merely coincidental occurrences of ocular troubles. From his own investigations, he could confirm Dr. Floyd's conclusion that complaints against fuorescent lighting often proved to have a different basis. Referring to flashing beacons at pedestrian crossings, a speaker thought it unfortunate that they do not adequately illuminate anyone using or waiting to use the crossing. As to the red 'stop' lights on cars, another speaker claimed that experiments have demonstrated that these should be of 50 candelas for seeing at a distance of $\mathbf{5 0}$ yards when a driver is dazzled by opposing headlights.

\title{
GENETICS AND PLANT BREEDING
}

A JOINT session at Bristol of Sections K (Botany) and $M$ (Agriculture) of the British Association was devoted to a symposium on "Genetics and Plant Breeding". The range of contributions to the symposium emphasized not only the scientific bases of present-day plant-breeding programmes, but also the dependence of advanced communities on a constant, integrated attack on those limiting factors to yield and quality which can be overcome by the genetical approach to crop improvement. A guaranteed standard of living, which advanced peoples have come to regard as a birthright, and which is now recognized as an international responsibility so far as the less-developed peoples are concerned, demands maximum efficiency from the germ plasm in food production. Not only must crop plants produce maximum yields at economic levels, but also quality, variety and long-term reliability of the material in the face of epidemics and environmental variations must also be among their attributes. The interaction of food production and soil fertility over large areas of the world presents grievous problems which can only be solved satisfactorily by escaping from an exhaustive form of monoculture to a rotational culture based on species of plants yet to be isolated from Nature's repertoire. If it is to continue to serve advanced communities, the science of plantbreeding has to respond quickly to human progress in all directions, in changes of dietary needs, in advances in agronomy, in farm mechanization as well as in the grading and processing of the final product.

Dr. D. Lewis, of the John Innes Horticultural Institution, Bayfordbury, in his opening paper, suggested how genetics, although unable to produce plants to order, can offer a systematic approach towards such problems and possibilities by initially 'blue printing' the foundation genotypes as well as outlining methods whereby a desired genetic architecture can be constructed stepwise. The limits to the construction of gene recombinations are frequently set by close linkage, involving gene effects with opposing or compensating functions. The eventual attainment of genotypes as near as possible to the ideal often depends on the breakdown of these linked units of inheritance. This problem is one with which crop-improvement projects are constantly being faced, and reliable methods such as a temporary passage through a tetraploid condition or the application of physical environmental stresses at meiosis might profitably be perfected to achieve an immediate and permanent release of undesirable gene combinations. Similarly, the breakdown of the natural breeding system of a species can often aid materially in releasing variability as well as in ensuring reliability of cropping. Thus in cherries, mutations induced by $\mathrm{X}$-rays have yielded fully self-fertile genotypes which crop well even under adverse conditions for pollination by insects.

The importance of the part played by the breeding system in controlling variability and therefore in deciding the genetical approach to its improvement is nowhere better exemplified than in the genus Rubus, which was surveyed by Dr. G. M. Haskell (John Innes Horticultural Institution, Bayfordbury). Here apomixis is widespread, but in some instances variations in the mechanism allow of segregation and recombination among maternal chromosomes. Such sub-sexual processes give rise to greater variability than is often realized, and selection becomes possible. The segregation of quantitative characters within the sub-sexual apomict $R$. nitidioides (Merton Early) indicates that the improvement of economic characters such as earliness and intensity of prickles is possible, though the speed of selection will necessarily be slower than in fully sexual groups. Many apomictic species are also polyploids of various kinds, and a complete change to sexuality may reveal an unbalance characteristic of some polyploid groups. Thus in the Eubatus section of Rubus, broadly divisible into the mainly tetraploid group Moriferi veri, and the Corylifolii, which are largely pentaploid and are descended from the apomictic $R$. caesius, apomixis is widespread ; whereas in the section Idaeobatus, consisting predominantly 
of diploid species, sexual reproduction is normal. The breeding behaviour of both inter- and intragroup hybrids is therefore often complicated, and only the most thorough study of joint segregations of groups of characters will ensure the detection of sexual progeny from the sub-sexuals and the apomicts. It is through such investigations on breeding behaviour and on the genomic constitution of species and varieties that the breeder can make full use of all the variability potential of his material.

Among the most helpful genetic concepts in plant breeding that have been developed in recent years are those elaborated by Prof. K. Mather in his studies on variability, in which variation is classified as free or potential. In homozygotes, all the variability is free and, discounting mutation, it is in a fixed state. If the breeding system allows, populations of homozygotes possessing maximum immediate fitness will be developed. Heterozygotes, however, contain potential variation which can only be freed at meiosis in sexual reproduction. Where the number of heterozygous loci is large, and where close linkage preserves gene combinations in a heterozygous condition, as it inevitably must in many cases, the problems of freeing the potential variation in heterozygous material become very real. Dr. A. J. Bateman (Christie Hospital and Holt Radium Institute, Manchester) emphasized that the upper limits of selection are governed by the methods that are used to realize the potential store of variability in heterozygotes. Using methods designed to exhaust the genetic potential, notions on the selection limits of certain characters in living organisms often have to be radically revised. This has been clearly demonstrated in laboratory experiments on Drosophila and the mouse, while in Nature it has become expensively obvious in another direction among the parasitic Basidiomycete fungi. Such laboratory and natural successes from new releases of variability underline the need for studying every aspect of plant-breeding procedure to ensure that crop improvement programmes shall not be allowed to rest on what well may turn out to be false selection limits.

One successful method of transcending selection limits has been the utilization of heterosis both in animals and plants. It is consistent with many aspects of the historical growth of science to find that immense benefits have followed the practical use of heterotic hybrids in food production, while we are still debating the nature of the precise genetic mechanism underlying the phenomenon. Mr. Watkin Williams (John Innes Horticultural Institution, Bayfordbury) developed a theme from which it could only be concluded that it was unnecessary and undesirable to partition heterosis into mutational euheterosis, balanced euheterosis, and luxuriance, after the scheme of evolutionists--notably Dobzhansky. Although it seems likely that the underlying genetic mechanisms controlling vigour are essentially the same in all these artificial categories, it does not follow that heterosis is always governed exclusively by any one mechanism in any given organism. Indeed, this is most unlikely, if only from analogy with the numerous mechanisms that are known to control discontinuous variation. The question of deciding between the two main theories of heterosis, namely, dominance with linkage as against the overdominance theory, has hitherto presented an insoluble problem. However, the failure of certain selection procedures in the American hybrid maizo programme indicates that the dominance hypothesis alone is insufficient to explain all the facts, while data on the biochemistry of heterozygotes, such as those of Pauling and Irwin, indicate the physiological mechanisms through which overdominance could operate. Thus an exclusive approach to heterosis is at present to be avoided, if maximum utilization is to be made of the various mechanisms which govern quantitative variation.

In no field of crop improvement is the basic approach so important as in selecting for resistance to disease. The breakdown in resistance which we have come to expect following the release of new varieties on a commercial scale has raised doubts in many minds as to whether the interplay between host and parasite can be settled in favour of the host. Dr. Lewis, from a survey of the literature, has concluded that genetic control seems more likely with insect pests than with fungal disease where chemical control appears to be more effective. An important consideration in this connexion was contained in a contribution by Dr. R. L. Knight (East Malling Research Station), in which it was suggested that the ease with which parasites form biological races may be correlated with a simple genetic mechanism controlling resistance in the host. Resistance based only on a few major genes may be more easily circumvented by a single mutation in the parasite. Complex resistances based on major genes, and reinforced by modifiers and polygenes introduced from a wide range of material, are on the contrary much less likely to be overcome by biological specialization in the parasite. The manipulation of complex resistances of this nature has been successfully accomplished with the cotton variety, Sudan Salkel, which is susceptible to attack by jassids. Here a bridging genotype had to be synthesized by back-crossing, to give a modified Sakel which in turn was used as the recurrent parent for the intensification of resistance through further transferences of polygenes affecting length and density of epidermal hairs. The scanning of a genus or of a species for sources of resistance involves the acquisition of a wide collection of genotypes from both wild and cultivated sources, and the maintenance of a large and expensive genetic museum of material. Nevertheless, in genera such as Solanum and Gossypium, where collections have been organized, valuable economic improvements have been achieved.

The regimentation of Nature's store of variability into collections for the ready use of the science of plant breeding needs to be interpreted in the last analysis as necessary organization for the benefit of humanity. Dr. G. D. H. Bell (Plant Breeding Institute, Cambridge) outlined the need for crop improvement in terms of the demands and responsibilities of the more advanced nations. World food production is now recognized as a world problem, and communities of people as they advance expend less and less of their energies on primary food production. 'Thus with vast new areas awaiting development on one hand, and shrinking acreages such as those of the British Isles demanding that maximum production be achieved at an economic level on the other, the plant breeder to-day is vital to survival. This sense of urgency has already been recognized both by sovereign countries and by international organizations such as the Food and Agriculture Organization and the Organization for European Economic Co-operation.

Notwithstanding such considerations, Dr. Bell emphasized that it is the need for the application of more scientific methods, and the great complexity 
of the problems to be solved, that have made necessary the provision of adequate and intelligent facilities for plant breeding. No longer can we afford to rely $n$ a division of science into the pure and the applied, and wait for a piece of research to be completed in its appropriate pigeon-hole before further progress is attempted. Nor can we expect a science without scientists, and the training of a plant breeder presents yet another of those educational problems which most university curricula have so far failed to solve.

WATKIN WILLIAMS

\section{UNIVERSITY OF OXFORD SCHOOL OF FORESTRY}

$\mathrm{O}$

October 1, the University of Oxford School of Forestry celebrated its golden jubilee in the Imperial Forestry Institute, which has been its home since 1950, and in St. John's College, which has been very closely associated with it throughout the fifty years of its existence. When the Royal Indian Engineering College at Coopers Hill (near Windsor) closed in 1905, training for the Indian Forest Service which had been given there since 1888 was transferred to Oxford, temporary accommodation having been secured to serve until the building promised by St. John's was ready. The director, Dr. (afterwards Sir William) Schlich, and his assistant W. R. Fisher brought over the current class of twelve probationers and thus opened the first university forestry school in Britain (or indeed the British Empire) though Edinburgh already had a lecturer in forestry. The senior of this group, A. E. Osmaston, officiated at the planting of a jubilee oak tree at the recent celebrations. This was done in Bagley Wood, which has been continuously available to the School through the generosity of St. John's, the owner of the wood for four centuries. Mr. Osmaston is one of a famous forestry family of which seven members are serving or have served in the Forest Services of India, Britain and the Colonies ; three were present on this occasion. He was assisted by one of the present students, and a gathering of about 130 persons, nearly all former students or members of the staff, witnessed the ceremony.

The jubilee address was delivered by Sir Harold Glover, one of the first students to read forestry in Oxford, his year being headed by the late Lord Robinson, sometime chairman of the Forestry Commission. Many of that year took degrees in natural sciences, as well as the Forestry Diploma. Sir Harold joined the Indian Forest Service, Oxford having been for some years the only training centre for Indian Service probationers; between 1907 and 1932, when recruitment in the United Kingdom ceased, 213 out of the total intake of 306 had passed through the School. The last five inspectors-general in India have been Oxford graduates, including the present holder of that important post.

In 1924, the School was strengthened by the establishment of the Imperial Forestry Institute to provide a centre for higher education and research for those parts of the Empire which needed such facilities: though the Institute was in no sense a part of the School, many facilities such as the library were shared, and members of the Institute staff undertook some of the teaching. The two organizations were amalgamated in 1938 to form the University Department of Forestry. In the early years, only a diploma was awarded on the work of the two or three years the course covered, but a pass degree was granted in 1918, and finally an honours degree in 1944.

The School has provided 144 recruits to the Colonial Forest Service, and since the opening of the Institute, practically all members of that Service have attended postgraduate courses in Oxford. The proportion of the officers of the United Kingdom Forestry Commission trained at Oxford has been lower, but forty-four are serving at present, and the Commission's research staff worked at Oxford before the research station at Alice Holt was established.

A lunch was given in St. John's College, the speaker being Sir Henry Beresford-Peirse, deputy directorgeneral of the Forestry Commission. He made particular reference to the very wide range of subjects covered in a university forestry course, giving it an educational value much beyond a technical training.

The average number of students over the past three years has been fifty-eight, and the number graduating twelve. There are at present students from the United Kingdom, Canada, New Zealand, South Africa, India, Pakistan, Burma, Ceylon and several Colonies. The staff now consists of the professor, one reader, sixteen demonstrators, twenty technical assistants, twelve secretarial and librarian employees and six others, and the annual expenditure approximates $£ 50,000$.

H. G. Champion

\section{OBITUARIES}

\section{Prof. H. K. Mookerjee}

THE death occurred very suddenly on August 18 of Prof. H. K. Mookerjee, professor and head of the Department of Zoology of the University of Calcutta. Born in 1898, Mookerjee's undergraduate days were spent in the Presidency College, Calcutta. He won the University Gold Medal in zoology in 1924, and joined the University as assistant lecturer in 1925. As the Guruprasanna Ghose Scholar, Mookerjee went to London in 1926, and worked in the Imperial College of Science and Technology under the late Prof. E. W. MacBride. His work on the development of the vertebral column attracted considerable attention. He was Sara Marshal Scholar in the Imperial College during 1927-28, and Ghose Travelling Fellow of the University of Calcutta during 1928-29. He was awarded the D.Se. of the University of London in 1930. He rejoined the University of Calcutta on his return, and in 1933 became the University professor of zoology, which post he filled with great credit until the end of his life.

Prof. H. K. Mookerjee's important contribution in the field of embryology and evolution was based on the study of development of the axial skeleton of practically all groups of the chordates starting from Balanoglossus right up to man. He pointed out further that the centrum of all the chordates is formed in the same manner according to a basic plan; in the development of the vertebral centrum of all the chordates, from Amphioxus up to the mammals, only notochord, chord sheath, and the pericordal tube formed around the latter, take part, according to Mookerjee, but not the arch-bases or other elements claimed previously. Besides this hypothesis, Mookerjee also pointed out the many characteristic changes that take place in a non-plastic organ like the vertebral column along with change 